Bidart Claire, Longo Maria Eugenia, Mendez Ariel, Aix Marseille Univ, CNRS, LEST, Aix-en-Provence, France

\title{
Time and process: an operational framework for processual analysis
}

\author{
Published in European Sociological Review, 29 (4), pp.743-751
}

(Authors' version)

Most social phenomena are processes, and like all processes they 'take time'. They are part of the flow of history; they evolve and, in doing so, produce changes themselves. However, the dynamic aspects of such phenomena are not always taken seriously in the social sciences. Time is often seen as a variable to be added to the others but without incorporating what it changes into what is observed. In other cases, authors focus on events and dates and processes are fragmented : the continuity of the story and its connection with the context can be forgotten.

Temporal objects should be subjected to processual analysis (Mohr, 1982, Pettigrew, 1990, Chiles, 2003 etc.). Such analysis aims to consider process in a narrative perspective, integrating the arrangement of elements, rather than measuring occurrences of events and variables. The purpose of this article is to take up the challenge of theorising processes. It will seek to develop a set of conceptual tools based on a linkage between time and the changes observed in the phenomena under investigation.

How can an individual or collective process be charted? How can a career trajectory or an industrial restructuring project be analysed? How are their specific dynamics, the changes they carry and their evolution in contexts that are themselves evolving to be investigated ? Is it possible to isolate elements and to reveal their arrangement, even though they are themselves evolving? What causes the change? In order to deal with questions such as these, we will propose a conceptual system that provides an overall view of the process. It is based on four key concepts: the ingredients derived from the context, the sequences, the driving forces and the turning points (Mendez, 2010). The precise definition of each of these concepts ensues from a number of theoretical debates, but in many cases these debates remain isolated from each other. Thus contexts are discussed but not sequences, or turning point are investigated but not the forces driving the changes. In this paper, such approaches are enriched through the association of these four concepts within an integrated analytical framework that gives meaning to processes by shedding light on the combination of elements and dynamics on which they are based. In the first part, we outline the main principles of this process theory. In the second part, each of the four pillars of the proposed framework for processual analysis is outlined. In the conclusion, it will be shown that it is by mobilising these four pillars together that the system produces its added value.

\section{Towards a processual analysis: the principles}




\section{Time and process}

Our approach was born out of the dissatisfaction due to the treatment of dynamics in many studies in the social sciences. Time, congealed or flattened, often plays no role in them. In some cases, social phenomena are presented as immutable structures or momentary interactions, an approach that 'denies' the effect of time. Arguments are couched in terms of 'substance', abstract or petrified entities, reified and atomised variables, without taking into account what has gradually forged those entities and variables and linked them to each other or what makes them evolve at any time (Emirbayer, 1997, Abbott, 2001). In other cases, time is external to the phenomenon. Duration is measured but does not lead to any reconsideration of the constituent elements of the phenomenon, as if they had not evolved in the meantime. Time is then reduced to a linear continuity detached from the perpetual transformations of realities (Giddens, 1991). At best, processes are divided up into a succession of snapshots which, duly combined, are supposed to represent chronological evolution. Time is treated as an external element which, when mobilised ex post, can help in the task of artificially assembling this set of coagulated observations.

In other cases, time plays a role but is approached synchronically which, by 'flattening' the process, reduces change to the initial objective or to the final outcome. In this 'ballistic' or 'archaeological' approach, the entire story is compressed to the starting or final point (de Coninck \& Godard, 1990).

However, a process takes time. A clock can measure its duration but does not indicate that something else is happening as the time passes. The chronological dimension establishes a homogeneous and continuous time, but other heterogeneous and discontinuous temporalities (as experienced times) also play a part in the process (Elias, 1996, Grossin, 1996). They define various 'temporal frameworks' resulting from the conjunction of a number of different objective and subjective reference temporalities as legislative, professional, familial ones (Adam, 1995). Now, the multiplicity and subjectivity of temporalities must be taken into account, since they have effects. A wide range of different factors (events, durations and careers, as well as perceptions and interactions), located at various levels, will have to be brought into play. These factors follow relatively asynchronous and non-linear logics.

Event history analysis and demography have seriously taken into account the effects of time and elaborated very sophisticated statistical and modelling methods in order to identify and compute sequences of events (Coleman, 1981; Allison, 1984, 2004; Blossfeld and Rower, 2002). But these methods remain focused on events and variables; they try to distinguish causalities (why did it occur and when?). In contrast, we aim to favour a more qualitative and integrated conception of process with embedded causalities (how did it happen?). Process is a combination of contexts, events (also) and dynamic interactions between them. We want to give an overview of the story in its developments. Our aim is to propose a processual analysis framework which enables to consider time without loosing the story. Phenomena acquire temporal 'depth' and are linked together in a multiplicity of ways. It is through processual analysis that this complexity can be reconstituted and understood.

Furthermore, time exerts its influence throughout the whole story. It has differentiated effects that make themselves felt one by one as the action proceeds, while being variable 
and cumulative. At one moment, the state of the question and the factors driving the transition are not the same as at another one. It is necessary, therefore, to break a process down, to take stock frequently in order to identify what has changed and what is getting ready for the next change. Thus analysts will separate out moments and combinations of elements in order to identify what, 'over the course of time', has changed and constructed the process. They will detect changes in the very constitution of the factors at work in the process and pinpoint events, changes of pace and critical situations. This analysis of the multiplicity of temporalities contained within a process leads to an understanding that cannot be reduced to the mere sum of the factors that produce it.

In the case of a process of vocational integration, the connections between situations and events, their temporal sequencing, have their own part to play. Let us take the case of young Alban, who was questioned on several occasions, at three-yearly intervals, as part of a longitudinal survey ${ }^{1}$. When he left secondary school, Alban wanted to start earning his living straightaway and embarked on a career in sales and marketing. Several years later, he resigned from his job and went to university to train as a dentist. What happened? His plans, his resources and his work dispositions all changed over time. Alban's situation and plans in 1995 and in 2007 cannot be analysed using the same information. In the meantime, his resources and priorities had changed. His experience of work and the gradual establishment of financial security played a role. Temporalities others than those of the world of work also played a part. Family circumstances (he had gone back to live with his mother) coincided with a certain degree of accumulated weariness with his sales job. The influence of these temporalities, each following its own particular logic, was to be mediated through the conjunction of various situations and events.

This complex conception of time leads to the abandonment of linear thinking and to the introduction into the analysis of a form of temporal discontinuity, a 'slicing' of time. Analysing a process is not simply a matter of being able to capture it in its entirety: one also has to be able to pinpoint the various changes it has undergone. Dividing a process up into separate stages is an essential analytical approach if the process is not to be reduced to its final outcome, if possible bifurcations are not to be ignored and if analysts are not to lose their bearings in the complexity of the process as a whole. Resources, constraints and plans are situated in time and the interactions between them change from one period to the next. This leads to consider processes as stories, i.e. as dynamic systems including changing contexts, sets of actions and events, driving forces and turning points; various sequences can then be separated out from each other in such a way that fresh consideration can be given to causalities which, particularly in a process, are multiple and interdependent (Abbott, 2001).

\section{Processes are stories}

A process has to be conceptualised as a story. It then becomes necessary to unravel it in order to make its progression intelligible (de Coninck and Godard, 1990).

According to Becker (1998), this approach genuinely entails a different method of working. He gives the example of marital breakdown, which is studied by sociologists of the family by

\footnotetext{
${ }^{1}$ This panel survey was carried out in France between 1995 and 2007 (see Bidart, 2006).
} 
looking for the factors that differentiate couples that separate from those who stay together (the variance). In his view, any analysis should better focus on the history of the breakdown, on the various stages of the process and the links between them, since each stage creates the conditions required for the next one to emerge.

In this approach, the distinction of different sequences of events is important. The time at which they occur is significant for a process. Two events $A$ and $B$ mean different things depending on whether $A$ takes place before $B$ or vice versa. The contexts and forces involved in the emergence of $A$ are different from the ones involved in the emergence of $B$. In his closely argued critique of the General Linear Model and the stochastic view, which wrongly dissociates and rigidifies the variables, Andrew Abbott (2001) advocates a narrative analysis that attributes three properties to 'stories': order (the extent to which a story presupposes a particular exact order to events), enchainment (the nature of the narrative link from one step to another) and convergence (the extent to which a given sequence achieves relative stability).

The importance of the enchainment of events becomes evident again in the 'eventful sociology' advocated by Sewell (1996), who argues in favour of an analysis in which the laws of causality are neither constant nor independent from one sequence to the next. This approach gives particular consideration to path dependency, namely the fact that the characteristics of the past have consequences for possible future outcomes. It also takes into account the change in contexts and structures, including the most enduring ones, brought about by events. Now, social and biographical processes are made of sequences of events that are to a large extent contingent.

\section{Multiple and interdependent causalities}

This attempt to clarify process time stands in complete contrast to simple causal analyses and it seeks to foster an understanding of the way in which the various constituent elements of a process relate to each other. A narrative story expresses, above all, ties projected into a context (White, 2008). Emirbayer (1997: 308) proposes to 'unfreeze' factors by reintroducing their dynamic dimension together with their relational dimension. In contrast to variance analyses, which seek to identify a causal relationship between independent and linear variables, processual analyses consider the multiple, time-related and interwoven nature of causalities. In linear causality, it is assumed that a factor $X$ has a corresponding effect $Y$; processual analysis, on the other hand, locates the successive values of $X$ in time, narrates its story, describes the different states it passes through as it evolves and shows that the effect $Y$ does not occur at just any random point in time (Blossfeld, 1996). It also considers the multiplicity of factors that contribute to it, with their heterogeneous scales, natures and temporalities, the idea being that it is the synchronised combination of these factors that produces the effect $Y$ and not simply the factor $X$. Adopting a diachronic perspective, it emphasises the way in which the history of the various factors plays a part in their conjunction and in the effects they produce at any given moment.

Thus Becker separates the 'why', which calls for a single cause, from the 'how', justifying his choice as follows: 'I wanted to know the sequences of things, how one thing led to another, how this didn't happen until that happened' (Becker, 1998: 60). Efforts to answer such questions lead to the rejection of multivariate analysis in favour of sequential analysis, in which it is accepted that the various factors at work do not exert their influence at the same 
time or in a linear way. The successive positions of the process's constituent elements produce different effects and thus have to be distinguished.

Thus processual analysis examines bundles and configurations of elements derived from the context, rather than isolated elements. It marks a shift away from explanations couched in terms of outcomes and their causes, towards the development of a story. Here lies a clear distinction between narrative and variable-based conceptualisations of processes: 'You don't look for invariant effects of causes, but for stories whose steps have a logic, perhaps even a logic as inevitable as the logic of causes. From this point of view, events are not caused by anything other than the story that led them to be the way they are. Social scientists call stories with these characteristics processes' (Becker, 1998: 61). Nevertheless, the singularity of these stories is not the main point of attention, as one can find in them recurrent logics and combinations of situations and actions.

\section{A framework for processual analysis}

The principles that underpin processual analysis lead us to structure it around four linked concepts. The historical nature of a process means, firstly, that it is embedded in a context from which are derived certain elements (situations, events, actions) that play an active role in the process, in a both contingent and enduring way, which are denoted by the term 'ingredients'. These ingredients never operate in isolation as a single cause of the change that is observed. It is the linkage between them, the order in which they emerge and the way in which they combine that conspire to produce the process. The configuration of these contextual ingredients varies over the course of a given process, since 'time matters' (Abbott, 2001). These changes make it possible to identify different sequences throughout the process. Sequences, from our point of view, mean more than "steps" of Becker's stories, more than episodes, as they are made of a specific and temporary configuration of situated ingredients. In order to go beyond singularity, similar sequences can be identified in different processes. Sequences evolve under the influence of multiple causalities, which interact both synchronically and diachronically; this generates the driving force for change. This means the resultant dynamics from various levels of contexts, organisations and individuals, that give impulse to the process. It sometimes happens that changes in the orientation of the process are particularly pronounced, that certain events come to matter more than others, thereby indicating a turning point.

These concepts serve to define a process as 'a set of phenomena organised in time that combines ingredients and driving forces. Changes in their configuration can be used to identify sequences. When changes alter the very orientation of the process, they are turning points'. These four concepts have to be presented here separately, even though their added value in fact lies in the linkage between them.

\section{Contexts and ingredients}

To analyse a process is, firstly, to analyse phenomena that are evolving in a context defined a priori as 'the whole of elements present in a given situation'. Although the importance of context has been affirmed by many authors, it has not systematically been incorporated into analyses. The way in which context is treated frequently leads to it being neutralised. 
Sometimes it is explicitly included as a dimension of the analysis, but in a reified way, as if it were merely a setting serving as a backdrop to the social dynamics. In other studies context plays a part in the process but within a profoundly structuring, even deterministic relationship. For us, a process maintains a complex, non-deterministic relationship with the context in which it unfolds. Every process is embedded in a context that is structured by a number of elements. The process in turn acts on the context, generating new elements that help to change it. Thus the relationship between process and context is one of mutual coconstruction. The reflexive nature of the relationship also echoes the notion of indexicality developed by ethnomethodologists: an action cannot be interpreted without reference to a context and the context cannot be described without reference to this action, since one helps to define the other and vice versa (Garfinkel, 1984).

One of the stumbling blocks in attempting to incorporate context into a processual analysis is the impossibility of depicting contexts in their entirety. However, it is not necessary to do so. Analysis of the context of a process in fact involves identifying the ingredients that are crucial to its development. These ingredients are defined as the 'elements of the context that are relevant to the process'. In any given context, only a certain number of the present elements are relevant. The selection of what is relevant to a situation (or not) is determined by the boundaries and interactions between the interests at stake, the situations and the social distribution of knowledge (Berger and Luckmann, 1986). This being so, a process may include elements that are initially not relevant but which become so as the process unfolds. Dividing a process up into sequences makes it possible to re-examine the elements that are relevant throughout the analysis. The other elements are merely 'part of the scenery' but have no significance for the process.

The relevance of the contextual elements can be assessed by the 'permutation' method, in which the course of the process is compared with the course it might have taken if such and such an element had not been present. It can also be identified by a change of scale (Lahire, 1996), which alows a researcher to perceive whether the influence of such and such a contextual element is repeated in other cases, thus confirming its decisive effect on the evolution of the process. True, any evaluation of this relevance will often be based on presumption or plausibility, since the social sciences are unable to control all contextual variables (Passeron, 1991). This makes it necessary to proceed iteratively by not eliminating ingredients too hastily and re-assessing their relevance over the course of the process.

For example, in young Alban's process of vocational integration, various elements combine and interact. Some have greater significance than others, defining opportunities and constraints located on various levels: the historical and institutional framework of French society, which specifies the value of his personal qualification; the local labour market; the individual dimension of resources and experiences, as well as his family and its history, particularly his parents' difficult divorce. Each of these levels has its corresponding more subjective ingredients: the informal and cultural hierarchy of 'good' professions and successful careers, his family's ambitions for him, which he was aware of in formulating his plan to become a dentist ('Today, everybody acknowledges me because I'm embarking on a prestigious course of study', Alban says).

Some of these ingredients have their roots in his past, like his Portuguese origins, the lack of money at home during his childhood, his dream of becoming a dentist, which was nipped in the bud before resurfacing under different conditions, and his early experience of work. 
Other ingredients relate to his family: his alcoholic father, his welcoming mother and his sister seen as 'a wonderful model of success'. However, whereas some trajectories are influenced by love affairs, Alban's relationship with Sylvie had no bearing on his choices, since he preferred to break it off rather than abandon his plans. So their relationship is not an ingredient in the process. Overall, the various ingredients combine with each other to form successive sequences punctuating the process of vocational integration.

\section{Sequences}

Some ingredients may be active at one point in the process and latent at others. This variability leads us to continue Abbott's work on sequences and to define them as 'temporal segments of a process that link together a specific set of ingredients'. Thus a process is made up of different sequences, each one being characterised by a (relatively stable) configuration of ingredients. Several different dynamics can bring about a change in these configurations: new ingredients may appear, while others that were active in earlier sequences may become dormant or disappear. Each time the configuration of ingredients is changed, a new sequence starts.

The identification of sequences is a constituent part of processual analysis. In a majority of studies, however, the 'time slicing' seems to be taken for granted and is not questioned conceptually. At best, it is investigated from a methodological perspective (Miles and Huberman, 1984, Aisenbrey and Fasang, 2010). Abbott $(1990,1995)$, on the other hand, puts forward a definition ('an ordered sample of things') that emphasises two dimensions: temporal succession and arrangement logic, to which we add interaction and internal dynamic. Sequences are not, after all, inert, nor are they mere methodological tools "ready for use". They contain ingredients that combine with each other in a particular configuration. This "thickness" and complex internal composition of sequences contribute to distinguish them from simple steps or episodes. A process finds its substance within sequences, in the interactions between a multiplicity of ingredients that influence each other, modifying their own meaning and that of the process as a whole. A unique dynamic develops, which may itself vary: sequences are more or less stable periods of interaction, and their internal rhythms have repercussions on the transition from one sequence to another. This may be the result of a sudden change provoked by unforeseeable exogenous events or of a slower change which, through an accumulation effect, may gradually shift the combination of ingredients into a new configuration. In the first case, the exogenous event disrupts the order of the elements at work in the current sequence and, through the constraints and resources offered by the new context, prefigures the characteristics of the new sequence. In the second case, the coming change is prepared within the sequence itself, in the particular interaction of the ingredients, even when the sequence seems relatively stable.

In all cases, the sequences have a form of coherence. However, while analysis of this internal organisation is fundamental, the interconnection between the sequences determines the process's overall direction. The succession of sequences is organised around a temporal logic characterised by irreversibility. This irreversibility stems from the impossibility of going back, or the excessive cost of so doing. It also extends to the meaning attributed by certain economists who have transposed the work of Prigogine to their own discipline (Boyer et al., 1991): each sequence retains, to a greater or lesser degree, the mark of the preceeding ingredients and sequences, and prepares the next ones. Thus the sequences are linked to 
the prior configurations, whether through breach or continuity, and they pave the way for the (probable and possible) future combinations of ingredients by virtue of their temporalities and internal dynamic.

To return to Alban's case, examination of his trajectory shows that it can be divided into three periods. In the first sequence, he embarks on a promising career that is the product of a particular combination of ingredients: a training in sales and marketing in large-scale retailing, his ambition to forge a career for himself, a money-oriented disposition to work as a means of compensating for the lack of money in his childhood, the good employment opportunities to be found in Paris and the satisfaction he derives from this social and material success. Nevertheless, certain duration effects are to be felt at the end of this sequence: Alban grows tired of working in sales and of living in Paris and feels reassured about his ability to earn money.

In the second sequence, some of the ingredients change: Alban is working in less favourable conditions, he returns to Normandy after his father's death to live with his mother, his dissatisfaction with his sales job grows stronger and his disposition to work has changed. The local employment opportunities prove to be disappointing and Alban finds it difficult to get established in marketing field. At the end of this sequence, Alban reassesses his situation and the contents of his work. A childhood dream (become a dentist) re-emerges. He actualises this idea again and draws up a plan to resume his studies.

In the third sequence, Alban is studying dentistry. He is still living with his mother, is spending the savings he has built up, feels no longer anxious about material comfort and is completely dedicated to his plan to become a dentist. Work becomes a means of personal and social development.

These three sequences are arranged in time: each one is a continuation of the preceding one, retaining some of its characteristics and making them "ageing" (resources, experiences and weariness accumulate), while incorporating new ingredients (a new job, living with his mother) or reviving old ones (the dream of becoming a dentist) in a specific combination. However, the force driving the action also plays a part in the process's evolution.

\section{Driving forces}

A process is characterised by movement. To understand a process is to explore its development over time, that is to analyse how the various ingredients and their configurations evolve and recombine in the course of the process. The notion of driving force describes 'a principle generating the movement of the ingredients and of their configurations over time'. This driving force derives from the combination of the respective dynamics of the contexts, ingredients, organisations and individuals involved in the process. For example, it can be the resultant of an individual's willingness combined with an organisational project in a certain crisis context, what will finally drive a certain kind of change.

This principle introduces a very different vision from that of experimental causality. The 'engine' metaphor, and that of mechanism that ensues from it (Hedström and Bearman, 2009), should not lead us to believe that the 'machinery' responsible for moving the process along is either excessively rigid or highly deterministic. The movement is rather generated by a number of different and sometimes contradictory principles. In most cases, several driving forces combine to give a process its unique trajectory. These driving forces may be of 
different kinds (Van de Ven and Poole, 1995). According to these authors, in the case of a 'programmatic' driving force, the change is contained within a programme that governs the process. The final state is known in advance, as are the sequences in the evolution towards that state and in their timing. A second type of 'evolutionary' driving force combines three mechanisms. Variations emerge within a population; they are retained or rejected by selection mechanisms; the selected variations can be reproduced. In the third type of 'dialectical' driving force, the tension between various ingredients impels the change. Here, the dynamics of the process result from the interplay of opposing forces. The fourth, 'teleological' driving force is based on the existence of a strong and explicit goal that guides the decisions and actions. The will to reach that goal constitutes the principle that generates the movement, which results from a series of decisions and actions that modify the ingredients and their configuration.

The term 'driving force' implies both movement and acceleration. However, such forces can also be a source of stability, if two of them counteract, if the movement they generate leads to deadlock or, in the event of failure, they even can become a source of regression.

Driving forces can be plural and assembled throughout the entire course of a process. They may be embedded, when a principal driving force is at work throughout a process, while others come into play during certain sequences or changes of direction. They may contradict each other when two forces are working one against the other by making ambivalent changes to the process's ingredients. They may also push in the same direction and accumulate, thereby mutually reinforcing each other.

Thus in Alban's trajectory, different modes of association can be observed. During the first sequence, his trajectory is driven by the cumulative effects of two forces. One is programmatic, since Alban is obliged to integrate into the world of work; this is a 'normal' stage in the transition into adult life. The other is teleological, since at the beginning of his working life, Alban expressed a strong project to establish a career in sales. In the second sequence, Alban begins to question his professional ambitions. Certain conflicting ingredients enter the picture and contribute to a reordering of the priorities on which Alban's plans had been based. During this sequence, this dialectical force combines with an evolutionary force: the shift in Alban's choices is linked to the shrinking of his opportunities at work. In the third sequence, finally, another driving force emerges, one that will structure all Alban's choices, namely his desire to become a dentist ('It's the best job in the world, someone who saves you from pain, he's like a god'). These successive driving forces contributed to generate the course of his career.

However, the analysis of a process cannot be complete without an understanding of the turning point that makes the trajectory change direction.

\section{Turning points}

A process may undergo radical shifts of direction. The concept of turning point helps to chronicle these major changes. It is defined as an 'intense rearrangement of the ingredients associated with an event, triggering a crisis and the emergence of an alternative and leading the process to change orientation'. The intensity and pace of the rearrangement and the scale of the change, together with its unpredictability and irreversibility, are the major criteria for identifying turning points (Grossetti, 2004). A turning point is a particular moment in the process, one more fraught with change than the preceeding and following 
sequences. Whereas the changes that occur in the course of a sequence affect only certain ingredients or their arrangement, a turning point constitutes an intense and radical change of direction that affects the process as a whole (Bidart, 2010). It is usually linked to a particular, extraordinary event that disrupts the expected course of events but cannot be reduced to the event itself.

Turning points have several characteristics. They are not continuous and gradual changes but rather complex and major changes that occur within a short space of time relative to the process under consideration. Their emergence is unforeseeable and they are seen as sudden, unexpected bend. The 'normal' course of events should have evolved differently. The radical nature of the change is another characteristic. It takes a very different direction from what was expected. This change of orientation is generally marked by an event in which it is crystallised. A fresh alternative is opened up, giving rise to a period of intense reflection. A turning point also implies the notion of crossroads, of a choice that has to be made between two paths at least. The scale of the change arises in particular out of the fact that it 'contaminates' the other spheres through an enchainment effect. This contributes to make it irreversible: it will be much more difficult afterwards to go back. Turning points are, after all, characterised by the discrepancy between the intensity of the change occurring over a relatively short period of time, and the scale of its impact for a long time in the following sequence. For Abbott (2001), this temporal specificity marks out 'turning points'.

Generally, an event suddenly disrupts the coherence of the ingredients' arrangement. Sometimes another event, described as resolvent, puts an end to a crisis situation that was perceptible in the previous sequence but for which no possible resolution could yet be envisaged. The event offers a way out of this crisis by opening up alternatives. The concept of turning point makes it possible to explore the 'depth' of the change. It takes account of the fact that, however intense they may be, radical changes of direction in a trajectory are seldom instantaneous. They take place within a certain time frame. The nature of the changes that take place in a turning point cannot really be understood unless what happens during that period is broken down very precisely.

For Alban, the conjunction of several ingredients, temporalities and events texplains the turning point. The transition from the first to second sequence prefigures it. Why does Alban leave this first, well-paid job for a worse job, why does he leave Paris to return to Normandy? An unpredictable event, apparently unconnected with his career path, namely his father's death, initiates this sequence. This event brings him closer to his mother ('I want to help her make up some of the lost time'). Another consequence is his reinterpretation of his trajectory. In particular, he wants to prove that a Portuguese immigrant's son can enter 'a good profession'. The impact of the destabilisation of these symbolic elements combines with ingredients that facilitate the actual change of direction. By living with his mother, Alban can do without a salary and resume his studies. An initial triggering event (the death of his father) initiates the crisis, while a second event (return to live with his mother) resolves it by creating a way out. The synchronisation of these ingredients gives them a meaning that they would not have had at any other time. Alban's job, his housing, his relationship with his family and his dream combine each other to produce the new vocational sequence. His father's death would not have produced the same effects in a different context, particularly if he had been happier in his work. 


\section{Conclusion: an integrated analytical framework}

The four conceptual pillars, temporarily separated out from each other for the purpose of the analysis, have to be deployed jointly if the process is to be revealed in its entirety. Together, they constitute an integrated framework for processual analysis and this combination produces their 'added value'.

After all, while identification of the relevant contextual elements, that is the ingredients, certainly constitutes the first level of the processual analysis. The researcher's work in dating and linking these ingredients together in order to reveal coherent sequences is essential if they are not to remain as mere lists without any explanatory power with regard to the process being analysed. Furthermore, if they remain isolated from each other and are considered as linear variables independent of each other, their modes of action will remain obscure and the advances will be limited. The ingredients in the process function in the same way as the ingredients in a culinary recipe; without them, it is impossible to produce the dish but taken separately they will never constitute a meal.

The sequences exist only because they are made up of ingredients. However, they cannot be incorporated into the processual analysis until the movement-generating principle has been defined. Without the addition of such a principle, the sequences remain inert and researchers cannot explain either their enchainment or the way in which they acquire meaning in the process as a whole. Without the driving forces, the sequences are simply chronological segments. With the driving forces, the analysis moves from snapshot to film.

It might be thought that the presence of driving forces and the identification of one or more movement-generating principles would ultimately be sufficient to understand and interpret a process. However, without taking account of the turning points, that is the radical changes of orientation, a processual analysis will reveal only a continuous outline, in which the various sequences succeed each other in a merely mechanical enchainment. If the sequences and turning points remain unidentified, an analysis based on driving forces alone would lack both temporality and structure.

The turning points, for their part, cannot be identified unless the researcher is able to reveal the configurations adopted by the ingredients and compare them with those coming before and afterwards. Unless the sequences are identified, thereby making it possible to compare the configurations of ingredients at different points in time and to identify the periods of most intense change, it would be difficult to map the turning points, that is the major restructurings of the ingredients.

A non processual analysis of labour market integration would undoubtedly have revealed Alban as a young man who finally succeeds in embarking on the course of study he has dreamt of, while ignoring the whole process of evolution and maturation that his plans had been through. It would not have made it possible to identify the relevance of the ingredients whose configuration at a given time put a new light on everything (his father's death, his return to his mother's home), the order of the sequences (a well-paid first job followed by a less satisfactory one that brings him closer to his mother and leads to disenchantment with his work), the change in the forces driving the action (working for money, then for prestige), with the whole process leading to a change of orientation (reactivation of his childhood dream, synchronised with the possibility of reducing his earnings and resuming his studies). It is undoubtedly the analysis of the synchronised configuration of these ingredients, 
arranged in separate sequences, driven by different forces and pushed in a different direction at a major turning point that enables us to understand the process.

This system of processual analysis is not limited to conceptual considerations, nor to individual singular cases. The recurrence of identified sequences, driving forces and bifurcations has been empirically tested for different populations in different contexts and countries. It has been applied to organisational studies too (FFF, 2010). These crossdisciplinary examples of applications show its suitability for very diverse empirical studies of processes.

\section{References}

Abbott, A. (1990). A Primer on Sequence Methods, Organization Science, 1: 4, 375-392.

Abbott, A. (1995). Sequence Analysis: New Methods for Old Ideas, Annual Review of Sociology, 21, 93-113.

Abbott, A. (2001). Time Matters : On Theory and Method. Chicago: University of Chicago Press.

Adam, B. (1995). Timewatch. The Social Analysis of Time. Cambridge: Polity Press.

Aisenbrey, S. and Fasang, A. (2010). New Life for old Ideas: The "Second Wave " of Sequence Analysis bringing the course Back into the Life Course, Sociological Methods and Research, 38: 3, 420-462.

Allison, D. Paul (1984). Event History Analysis. Beverly Hills: Sage Publications.

Allison, Paul D. (2004). Event history analysis. in Bryman, A.E. and Hardy, M. (eds.), Handbook of Data Analysis. Thousand Oaks, CA: Sage, 369-386.

Becker, H. S. (1998). Tricks of the Trade: How to Think about Your Research While You're Doing It. Chicago: University of Chicago Press.

Berger, P. and Luckmann, T. (1986). La construction sociale de la réalité. Paris: Méridiens Klincksieck.

Bessin M., Bidart C., Grossetti M. (ss. dir.), 2010, Bifurcations. Les sciences sociales face aux ruptures et à l'événement, Paris, Ed. La découverte, coll. Recherches.

Bidart, 2006, Panel "Sociabilité et insertion sociale" : une enquête longitudinale. Processus d'entrée dans la vie adulte, insertion professionnelle et évolution des réseaux sociaux. Note méthodologique disponible sur http://halshs.archivesouvertes.fr/view by stamp.php?\&halsid=1kco4fqu9v3ji7ee4s0de2ap45\&label=SHS\&la ngue $=$ fr\&action todo=view\&id=halshs-00118258\&version $=1$

Blossfeld, H.P. (1996). Macro-sociology, Rational Choice Theory, and Time. A Theoretical Perspective on the Empirical Analysis of Social Processes, European Sociological Review, 12: 2, 181-206.

Blossfeld, H.-P. and Rohwer, G. (2002) Techniques of Event History Modelling: New Approaches to Causal Analysis. New Jersey: Lawrence Erlbaum Associates.

Boyer, R., Chavance, B. and Godard, O. (1991). La dialectique réversibilité-irréversibilité : une mise en perspective. in Boyer, R., Chavance, B. and Godard, O. (Eds), Les figures de I'irréversibilité en économie. Paris : Editions de l'EHESS, 11-33

Chiles, T.H. (2003). Process Theorizing: Too Important to Ignore in a Kaleidic World, Academy of Management Learning and Education, 2: 3, 288-291.

Coleman, James (1981). Longitudinal data analysis. NY: Basic Books.

Coninck, F. (de) and Godard, F. (1990). L'approche biographique à l'épreuve de I'interprétation. Les formes temporelles de la causalité, Revue Française de Sociologie, 31: 1, 23-53.

Elias, N. (1984). Über die Zeit. Arbeiten zur Wissenssoziologie II. Frankfurt: Michael Schröter. [Traduction française : Du temps. Paris : Fayard, 1996]. 
Emirbayer, M. (1997). Manifesto for a Relational Sociology, The American Journal of Sociology, 103: 2, 281-317.

Garfinkel, H. (1984). Studies in Ethnomethodology. Cambridge: Polity Press.

Giddens, A. (1991). Modernity and Self-Identity. Self and Society in the Late Modern Age. Cambridge: Polity Press.

Grossetti, M. (2004). Sociologie de l'imprévisible. Paris : PUF.

Grossin, W. (1996). Pour une science des temps. Introduction à l'écologie temporelle. Toulouse : Octares.

Hedström, P. and Bearman, P. (Eds.) (2009). The Oxford Handbook of Analytical Sociology. Oxford University Press.

Lahire, B. (1996). La variation des contextes dans les sciences sociales. Remarques épistémologiques, Annales. Histoires, Sciences sociales, 51: 2, 381-407.

Mendez (dir.), 2010, Processus. Concepts et méthode pour l'analyse temporelle en sciences sociales, Louvain la Neuve, Academia Bruylant

Miles, M. and Huberman, M. (1984). Analysing Qualitative Data: A source Book For New Methods. Beverly Hills. CA: Sage.

Mohr, L.B. (1982). Explaining Organizational Behavior. San Francisco: Jossey-Bass.

Passeron, J.C. (1991). Le raisonnement sociologique: l'espace non poppérien du raisonnement naturel. Paris : Nathan.

Pettigrew, A. (1990). Longitudinal Field Research on Change: Theory and Practice, Organization Science, 1: 3, 267-292.

Sewell, W.H.Jr. (1996). Three Temporalities: Toward an Eventful Sociology, in Mc Donald, T.J. (Ed.), The Historic Turn in the Human Sciences. Ann Arbor: The University of Michigan Press, 245-280.

Van De Ven, A.H. and Poole, M.S. (1995). Explaining Development and Change in Organizations, Academy of Management Review, 20: 3, 510-540.

White, H. (2008). Identity and control : How social formations emerge. Princeton: Princeton University Press. 